\title{
Targeting granulocyte-macrophage colony-stimulating factor in epithelial and vascular remodeling in experimental eosinophilic esophagitis
}

\author{
E. N. McNamee $1,2,3,4$, K. A. Biette ${ }^{1,2,3}$, J. Hammer ${ }^{1,2,3}$, R. Harris ${ }^{1,2,3}$, H. Miyazawa ${ }^{1,2}$, J. J. Lee ${ }^{5}$, \\ G. T. Furuta ${ }^{1,2,3} \&$ J. C. Masterson ${ }^{1,2,3}$ \\ ${ }^{1}$ Department of Pediatrics, Gastrointestinal Eosinophilic Diseases Program, Section of Pediatric Gastroenterology, Hepatology and Nutrition, \\ University of Colorado School of Medicine; ${ }^{2}$ Digestive Health Institute, Children's Hospital Colorado; ${ }^{3}$ Department of Medicine, Mucosal \\ Inflammation Program, University of Colorado School of Medicine; ${ }^{4}$ Department of Anesthesiology, University of Colorado School of \\ Medicine, Aurora, CO; ${ }^{5}$ Department of Biochemistry and Molecular Biology, Mayo Clinic, Scottsdale, AZ, USA
}

To cite this article: McNamee EN, Biette KA, Hammer J, Harris R, Miyazawa H, Lee JJ, Furuta GT, Masterson JC. Targeting granulocyte-macrophage colonystimulating factor in epithelial and vascular remodeling in experimental eosinophilic esophagitis. Allergy 2017; 72: 1232-1242.

\section{Keywords}

eosinophil; epithelial; esophagitis; granulocyte-macrophage colony-stimulating factor (GM-CSF); GM-CSF receptor.

\section{Correspondence \\ Joanne C. Masterson, PhD, 12700 East \\ 19th Ave, C226, Aurora, CO 80045, USA. \\ Tel.: 3037243207 \\ Fax: 3037243212 \\ E-mail: joanne.masterson@ucdenver.edu}

Accepted for publication 3 December 2016

DOI:10.1111/all.13105

Edited by: Hans-Uwe Simon

\begin{abstract}
Background: Eosinophilic esophagitis (EoE) is a chronic antigen-mediated clinicopathologic disease of the esophagus characterized by an eosinophil-predominant inflammatory infiltrate. A clinical hallmark is extensive tissue remodeling including basal zone hyperplasia, fibrosis, and angiogenesis. However, the cellular mechanisms responsible for these processes are not fully defined. We hypothesized that targeting granulocyte-macrophage colony-stimulating factor (GM-CSF; an agonist cytokine linked with eosinophil survival and activation) would be protective in a preclinical model of EoE.

Methods: Eosinophilic esophagitis-like esophageal inflammation was induced in the L2-IL5 ${ }^{\text {OXA }}$ EoE mouse model, and GM-CSF production was assessed by mRNA and protein analyses. Granulocyte-macrophage colony-stimulating factorreceptor-alpha expression patterns were examined by flow cytometric and immunofluorescence analysis. L2-IL5 ${ }^{\text {OXA }}$ EoE mice were treated with anti-GMCSF neutralizing antibody or isotype control and assessed for histopathological indices of eosinophilia, epithelial hyperplasia, and angiogenesis by immunohistochemistry and RT-PCR.

Results: Significantly increased levels of esophageal GM-CSF expression was detected in the L2-IL5 ${ }^{\mathrm{OXA}}$ mouse EoE model during active inflammation. Granulocyte-macrophage colony-stimulating factor-receptor-alpha was predominantly expressed on esophageal eosinophils during EoE, in addition to select cells within the lamina propria. Anti-GM-CSF neutralization in L2-IL5 ${ }^{\text {OXA }}$ EoE mice resulted in a significant diminution of epithelial eosinophilia in addition to basal cell hyperplasia and vascular remodeling. This treatment response was independent of effects on esophageal eosinophil maturation or activation.

Conclusion: Granulocyte-macrophage colony-stimulating factor is a potential therapeutic target to reduce esophageal eosinophilia and remodeling.
\end{abstract}

Eosinophilic esophagitis (EoE) is a chronic antigenmediated clinicopathologic disease of the esophagus. A histologic and diagnostic hallmark of EoE is the accumulation of an eosinophil-predominant inflammatory infiltrate within esophageal mucosa. Eosinophilic esophagitis, like other atopic diseases, is growing in incidence and prevalence $(1,2)$. Existing medical treatments of EoE are limited to topical corticosteroids, diet restrictions, and esophageal dilation. However, these approaches have been associated with side-effects and negative impact on quality of life $(3,4)$. Moreover, the recent use of available biologics targeting eosinophils has not achieved clinical efficacy, thus leading to the need for identification of new therapeutic targets $(5,6)$. 
Granulocyte-macrophage colony-stimulating factor (GMCSF) was first defined because of its ability to generate colonies of mature granulocytes and macrophages from myeloid progenitors in vitro and is now known as a key mediator of eosinophilopoiesis. Granulocyte-macrophage colony-stimulating factor is induced by bacterial endotoxins and certain cytokines in many cell types including leukocytes (i.e. macrophage, mast cells, and $\mathrm{T}$ cells) and nonleukocytes (i.e. fibroblasts, endothelial, mesothelial, and epithelial cells) with actions on cells expressing the GM-CSF-R $\alpha$ such as eosinophils, basophils, DC-like cells, monocytes/macrophages, and neutrophils. Besides eosinophil progenitor proliferation and maturation, GM-CSF is now recognized to have a range of functions on mature eosinophils including dose-dependent eosinophil priming, migration, and degranulation (7-9). In addition, GM-CSF may also induce angiogenesis in multiple tissues by activating both proliferation and migration of endothelial cells (10-13).

We hypothesized that targeting GM-CSF would be protective in a preclinical model of EoE. The purpose of this study was to evaluate the potential use of an anti-GM-CSF antibody treatment on the inflammatory patterns related to esophageal eosinophilia, epithelial basal zone hyperplasia, and angiogenesis as a measure of postinflammatory epithelial remodeling. Using our previously described L2-IL5 OXA mouse model of EoE (14), we show that treatment with an anti-mouse GM-CSF monoclonal antibody significantly reduced epithelial eosinophilia, basal cell hyperplasia, and angiogenesis. The data support the importance of GM-CSF in the accumulation of eosinophils in EoE, suggesting it as a potential target for further clinical investigation.

\section{Materials and methods}

\section{Mice}

All studies were performed with male or female L2-IL5 mice on a $\mathrm{C} 57 \mathrm{BL} / 6 \mathrm{~J}$ background generated as previously described (14). Animals were maintained in micro-isolator cages housed in a specific-pathogen-free facility at the University of Colorado. Age- and sex-matched L2-IL5 mice were used as controls. Studies involving animals were performed in accordance with National Institutes of Health, University of Colorado IACUC guidelines.

\section{Induction of experimental EoE in L2-IL5 ${ }^{\mathrm{OXA}}$ mice using 4- ethoxymethylene-2-phenyl-2-oxazolin-5-one (oxazolone or OXA)}

Induction of esophageal eosinophilic inflammation in mice (L2-IL5 ${ }^{\text {OXA }}$ EoE) was established using a 4-ethoxymethylene-2-phenyl-2-oxazolin-5-one (oxazolone or OXA) (Sigma, St Louis, MO, USA) contact hypersensitivity protocol as previously described (Fig. 3A) (14). Briefly, on day 0 of the protocol, anesthetized mice were shaved on the abdomen and oxazolone was applied to the skin surface $(150 \mu \mathrm{l}$ of a $3 \%(\mathrm{w} / \mathrm{v})$ solution of OXA in $4: 1$ acetone-olive oil vehicle) to initiate the sensitization phase of the protocol (15). On days 5,8 , and 12 , mice were challenged by an intra-esophageal gavage of $100 \mu \mathrm{l}$ of a $1 \%(\mathrm{w} / \mathrm{v})$ OXA in $30 \%$ ethanol/ olive oil vehicle. Vehicle control L2-IL5 mice were sensitized as above and challenged with vehicle alone. All mice were assessed $24 \mathrm{~h}$ following the last OXA challenge (protocol day 13).

In some studies, a GM-CSF depleting antibody was administered to mice. These studies were completed using a monoclonal rat IgG2a antibody specific for murine GM-CSF (Clone \# MP122E9) or monoclonal rat IgG2a isotype control antibody (Clone \# 54447; R\&D Systems, Minneapolis, MN, USA). Experimental animals were injected with four intraperitoneal (i.p.) doses of anti-GM-CSF antibody ( $0.5 \mathrm{mg} /$ mouse) or IgG2a isotype control on days $5,8,10$, and 12 during experimental esophagitis (Fig. 3A). Mice were killed $24 \mathrm{~h}$ following final treatment (day 13).

\section{Tissue processing and immunohistochemical assessment of tissues}

Whole-length esophageal tissues were removed and fixed with $10 \%$ neutral-buffered formalin, processed, paraffinembedded, and cut into 5- $\mu \mathrm{m}$ sections. Sections were stained with hematoxylin and eosin (H\&E) (Sigma) or subjected to immunohistochemistry for eosinophil major basic protein-1 (MBP-1; Clone MT-14.7) (Lee Labs, Mayo Clinic, AZ, USA), Ki67 (Dako, Carpinteria, CA, USA) to assess cell proliferation, both as previously described (14) or CD31 (PECAM) (Abcam, Cambridge, MA, USA). MBP-1 immuno-positive cells were visualized with permanent red chemotrope, Ki67 immuno-positive cells were visualized with DAB chemotrope (Dako), and the slides were counterstained with Methyl Green (Vector Laboratories, Burlingame, CA, USA). CD31 (PECAM) immunopositive cells were visualized with a fluorescently tagged Alexa Fluor 488 antibody (Invitrogen, Grand Island, NY, USA), and slides were counterstained with DAPi (Invitrogen). Control sections replaced the primary antibody in each case with a rat IgG isotype control antibody (Vector Laboratories). Quantification of either MBP-1 or Ki67 immuno-positive cells was determined by gathering the numerical averages of nine nonoverlapping high-power fields $\left(0.26 \mathrm{~mm}^{2}\right)$ per esophagus (three distal, three mid, and three proximal). Mean vessel density was determined as previously described (16) from an average of nine nonoverlapping high-power fields per esophagus (three distal, three mid, and three proximal). Numbers are presented as a mean \pm SEM.

\section{Esophageal leukocyte isolation, quantification, and flow cytometric analysis}

Esophageal leukocytes were isolated as previously described (14). Briefly, esophagi were resected, cut longitudinally, washed in PBS, and then digested with collagenase (Sigma) as previously described for other intestinal tissues (17). Cell counts and viability of recovered leukocytes were determined with a hemocytometer and trypan blue exclusion. 
Single-cell suspensions were blocked using $1 \mu \mathrm{g} / \mu \mathrm{l}$ of $\mathrm{Fc}$ blocker (CD16/32; eBiosciences, San Diego, CA, USA). Cells were then stained for $2 \mathrm{~h}$ at $4^{\circ}$ with cell type-specific antibodies. Antibodies used for the staining of specific cell surface markers include GM-CSF-R $\alpha$ (698423), Ly6G (1A8), Ly6C (AL-21), IL-5R $\alpha$ (T21), CCR3 (83103), SiglecF (E50-2440) (BD Biosciences, San Jose, CA, USA); NK1.1 (PK136), MHC-II (M5/114.15.2), FceR1 $\alpha$ (MAR-1), CD200R3 (Ba13), CD80 (16-10A1) (BioLegend, San Diego, CA, USA); and CD11b (M1/70), CD34 (RAM34), CD45 (30-f11), CD49b (DX5), CD3e (145-2C11), CD19 (1D3), EPCAM (G8.8), CD69 (H1.2F3) (eBiosciences). Viable cells were determined with the use of Live/Dead AquaVi staining (Invitrogen). Flow cytometric analysis was performed using a BD FACSCanto ${ }^{\mathrm{TM}}$ II (BD Biosciences). Data files were further analyzed using FLOWJo software (Tree Star Inc, Ashland, OR, USA).

\section{Cell culture}

EPC2-hTERT immortalized human esophageal epithelial cells were cultured as previously described (18). EPC2hTERT cells were seeded at 60000 cells per well of a 24-well plate and $24 \mathrm{~h}$ after plating cells were switched to high-calcium $(1.8 \mathrm{mM})$ medium for a further $48 \mathrm{~h}$. Cells were then washed and treated for $24 \mathrm{~h}$ with varying concentrations of rhGM-CSF (R\&D Systems). Cells were harvested for mRNA analysis using RLT buffer from Qiagen RNeasy kits (Qiagen, Valencia, CA, USA).

\section{RNA isolation and real-time RT-PCR}

Total RNA was prepared from whole distal esophageal tissues with RNeasy Mini Kits (Qiagen) and handheld laboratory homogenizer (PRO Scientific, Oxford, CT, USA). Firststrand cDNA synthesis was performed from $500 \mathrm{ng}$ of total RNA using the High Capacity cDNA archive kit (Applied BioSystems, Foster City, CA, USA). Transcript expression was assessed using Taqman Gene Expression Assays Taqman probes (Applied Biosystems). rtRT-PCR was performed with ABsolute $^{\mathrm{TM}}$ Blue QPCR ROX Mix (Thermo Scientific, Surrey, UK). Thermocycling and analysis were performed with ABI-7300 System and software (Applied BioSystems, Foster City, CA, USA). Data were normalized to $18 \mathrm{~S}$ expression and calculated as RQ (Relative Quantity; $2^{-\Delta \Delta C_{\mathrm{t}}}$, where $C_{\mathrm{t}}$ is cycle threshold) for each sample.

\section{GM-CSF protein assessment of esophageal tissue}

Esophagi were resected, cut longitudinally to expose the luminal surface, washed in PBS, snap-frozen, and stored at $-80^{\circ} \mathrm{C}$ prior to use. Tissues were homogenized in MSD lysis buffer containing Roche complete mini protease inhibitor cocktail (Sigma) and assessed for GM-CSF protein content using a mouse GM-CSF-specific Mesoscale Assay (as per the manufacturer's instructions) [Meso Scale Diagnostics (MSD), Rockville, MD, USA] or total protein content using BCA Assay (Thermo Fisher, Waltham, MA, USA).

\section{Statistical analysis}

Statistical analyses of data outcomes were performed by Student's $t$-test. Data are expressed as means \pm SEM. A $P$-value of $\leq 0.05$ was considered as statistical significance although in some cases, higher levels of significance are noted and described in the figure legends where applicable. $* P \leq 0.05$, ${ }^{* *} P \leq 0.01, * * * P \leq 0.001$.

\section{Results}

\section{GM-CSF expression is increased in esophageal eosinophilia}

To understand the potential impact of GM-CSF on esophageal eosinophilia, we performed three sets of experiments (1). We first tested to see whether GM-CSF expression was elevated in the esophagus linked with the eosinophil-predominant inflammation occurring in the L2-IL5 ${ }^{\text {OXA }}$ mouse model of EoE. After 8 days, we examined both mRNA and protein expression in the esophageal tissue and found both to be significantly increased (mRNA: $1.3 \pm 0.3$ vs $9.0 \pm 1.9, P \leq 0.05$; Protein: $128 \pm 35$ vs $556 \pm 179 \mathrm{pg} / \mathrm{ml}, P \leq 0.05$, OXA $v s$ Veh-Ctrl) (Fig. 1A,B) (2). We tested whether GM-CSF would stimulate esophageal epithelial cells to release pro-allergic molecules given that epithelial cells exposed to GM-CSF are associated with perpetuation of atopic inflammatory conditions such as atopic dermatitis $(19,20)$. Our results showed that exposure of the human esophageal epithelial cells to rhGM-CSF induced the concentration-dependent production of GM-CSF in vitro (1.97 \pm 0.47 -fold increase, anti-GM-CSF vs IgG-Ctrl, $P \leq 0.05$ ) (Fig. 1C). (3) We went on to examine expression of the GM-CSF-R $\alpha$ in various myeloid-type leukocyte populations present during active inflammation in L2IL5 ${ }^{O X A}$ mouse EoE. Here, we found by flow cytometry that GM-CSF-R $\alpha$ was expressed at highest per-cell concentration on neutrophils and MHCII+ cells, and to a lesser degree on eosinophils and basophils (Fig. 2A,Bi). MHCII+ cells were further assessed and defined into three populations stratified as macrophage (live, single cells, CD45 ${ }^{+}, \mathrm{SiglecF}^{-}, \mathrm{Ly}_{6 \mathrm{C}}$, $\mathrm{MHCII}^{+}$), monocytes (live, single cells, CD45 ${ }^{+}, \mathrm{SiglecF}^{-}$, $\mathrm{MHCII}^{-}, \mathrm{Ly}_{6 \mathrm{C}}^{+}$), and dendritic cells (live, single cells, $\mathrm{CD}_{4}{ }^{+}$, SiglecF $^{-}, \mathrm{CD}_{11 \mathrm{c}^{+}}, \mathrm{MHCII}^{+}$) and presented as absolute cell numbers, with macrophage being the most abundant of these three MHCII bearing populations (Fig. 2Bii). Assessment of cell frequency in mouse esophagi found that neutrophils were rare compared to other leukocytes such as eosinophils (Fig. 2Bii). Immunofluorescent assessment of GM-CSF-R $\alpha$ and SiglecF revealed costaining for both to a significant degree compared to cells of the lamina propria that were positive for GM-CSF-R $\alpha$ alone (Fig. 2Ci-iii).

\section{Anti-GM-CSF antibody treatment attenuates esophageal epithelial eosinophilia}

We tested the hypothesis that depletion of GM-CSF protein by antibodies would reduce the esophageal eosinophilia in L2-IL5 ${ }^{O X A}$ EoE mice. Experimental groups of animals were given anti-GM-CSF antibody (via intraperitoneal injection, 

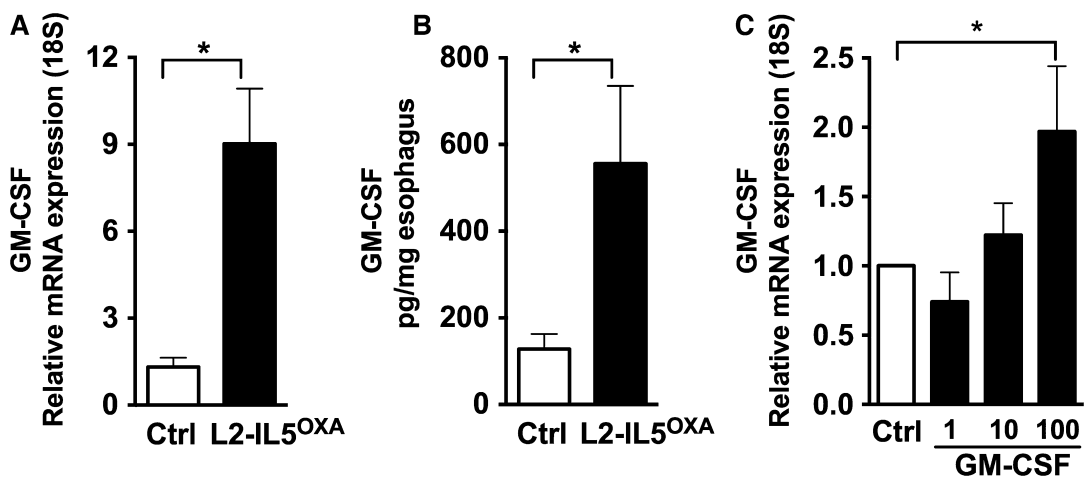

Figure 1 Molecular analysis of GM-CSF expression in the L2IL5 ${ }^{\text {OXA }}$ model of eosinophilic esophagitis (EoE). (A) mRNA and (B) protein expression in control (L2-IL5 ${ }^{\mathrm{VEH}} \mathrm{NTT}^{\mathrm{OXA}}$ ) and EoE (L2IL5 ${ }^{\mathrm{OXA}}$ ) mouse esophagi. (C) mRNA expression of GM-CSF transcript by esophageal epithelial cells following in vitro stimulation with a dose range of rhGM-CSF. Statistical significance was assessed using the Students' $t$-test, $* P<0.05$. Data are expressed as means \pm SEM.
A

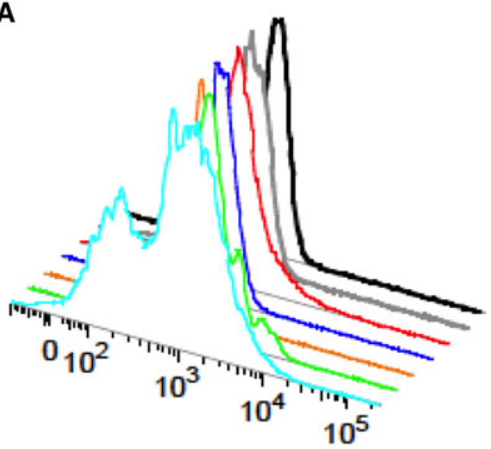

Bi L2-IL5OXA

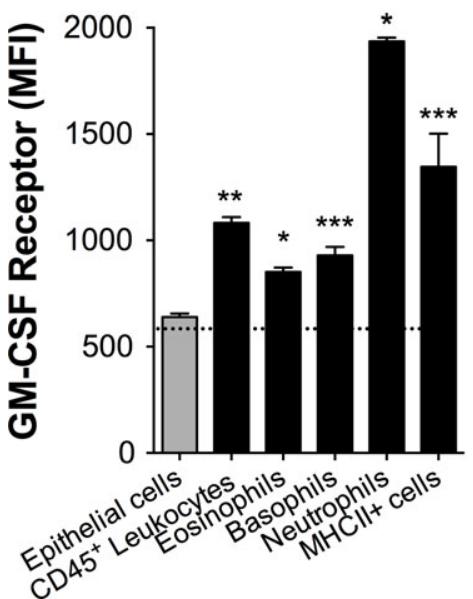

Figure 2 Eosinophils predominantly express GM-CSF-R $\alpha$ in L2 IL5 ${ }^{\text {OXA }}$ mice. (A) Histographical representation of GM-CSF-R $\alpha$ expression levels on cell populations from the esophagus of L2IL5 ${ }^{\mathrm{OXA}}$ eosinophilic esophagitis (EOE) mice by flow cytometric analysis. (Bi) Bar graph representation of mean fluorescence intensities (MFIs) for GM-CSF-R $\alpha$ on selected cell populations of the esophagus of L2-IL5 ${ }^{\mathrm{OXA}}$ EoE mice. (Bii) Absolute abundance of selected leukocyte populations per esophagus of L2-IL5 ${ }^{\mathrm{OXA}}$ EoE mice. Holm-
$\mathrm{Ci}$

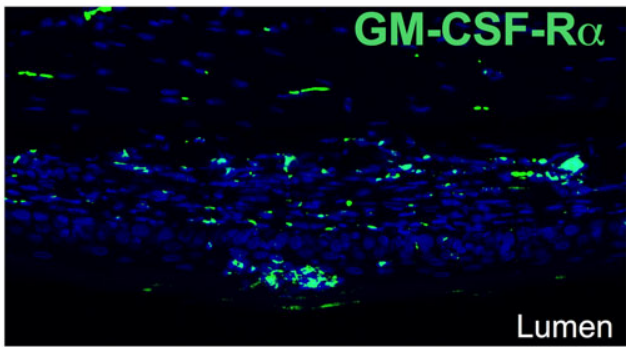

Cii

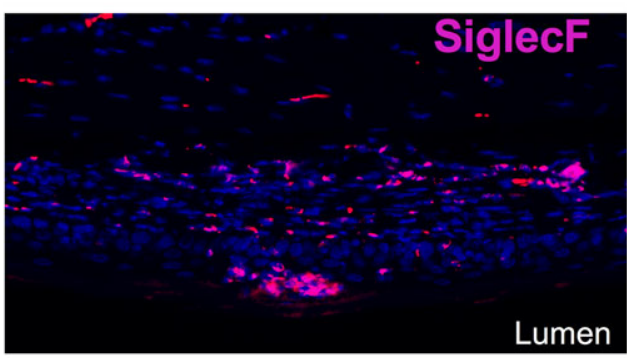

Cii

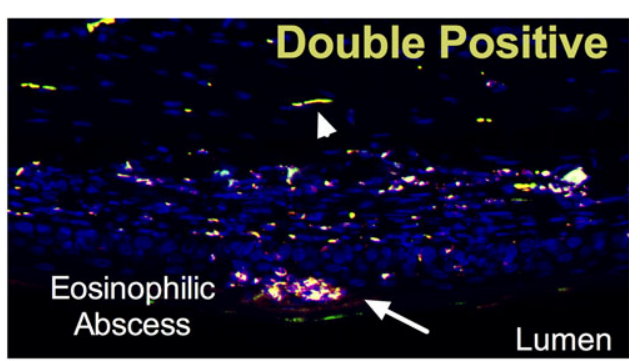


control animals received isotype-matched serum immunoglobulin) beginning day 5, the day of the first intraesophageal challenge and on days 8, 10, and 12 after induction of esophagitis (Fig. 3A). Anti-GM-CSF treatment lead to a significant decrease in epithelial eosinophilia as measured by counting intact eosinophils and assessing eosinophil MBP1 staining compared to anti-IgG2a isotype control-treated L2-IL5 ${ }^{O X A}$ EoE mice (Fig. 3B,Ci). The pattern of inhibition appeared to be most notable in the distal and middle esophagus. In addition, eosinophilia in the lamina propria was also reduced significantly (Fig. 3Cii) but no effect was observed on eosinophilia in the muscle layers (Fig. 3Ciii).

To elucidate whether these effects were locally restricted within the esophagus or were as a result of effects on eosinophil development and circulation, peripheral eosinophils were assessed from the spleen and bone marrow compartments by flow cytometry (Live, SSC-hi, CD $45^{+}, \mathrm{Ly}_{6} \mathrm{G}^{-}, \mathrm{SiglecF}^{+}$). No significant change was detected when quantifying peripheral eosinophilia (Bone Marrow: $3 \times 10^{6}$ vs $2.6 \times 10^{6}$, $P=0.46$; Spleen: $13.7 \times 10^{6}$ vs $12.7 \times 10^{6}, P=0.69$; Anti-

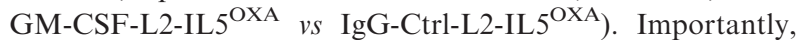
mice treated with anti-GM-CSF did not experience any effect on the overexpression of IL-5 in the esophagus $(1.4 \pm 0.4 \mathrm{vs}$ $0.98 \pm 0.1, P=0.3$; anti-GM-CSF-L2-IL5 ${ }^{\text {OXA }}$ vs IgG-CtrlL2-IL5 ${ }^{\text {OXA }}$ ). Thus, there was no observable effect on the baseline model system in the context of treatment and findings reported here were as a direct result of anti-GM-CSF on the inflammatory and remodeling consequences.
A

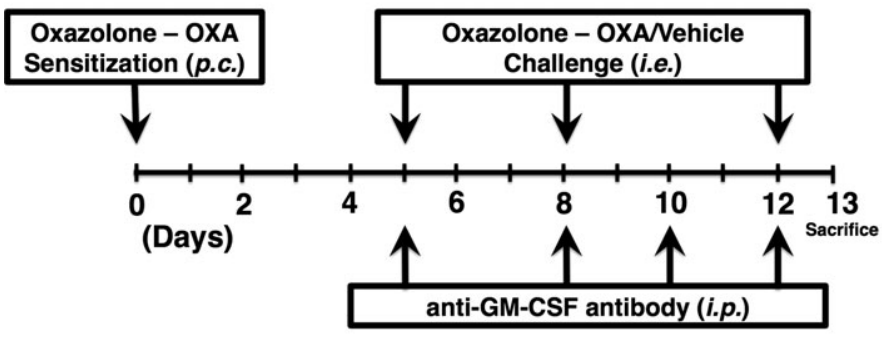

B
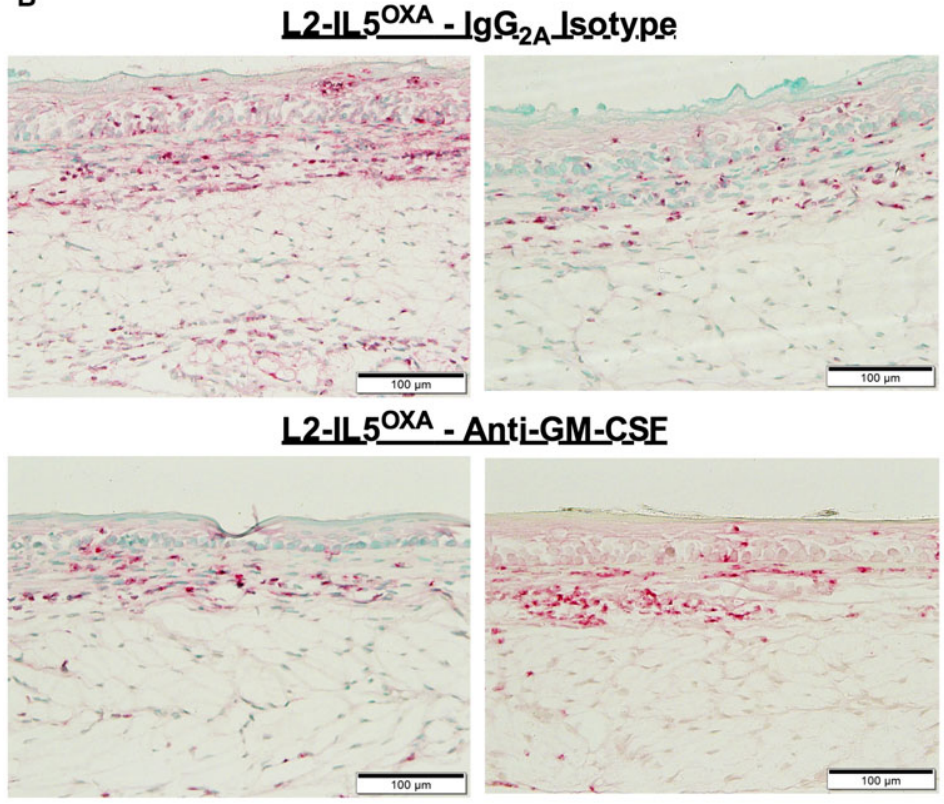

Ci Epithelial eosinophilia

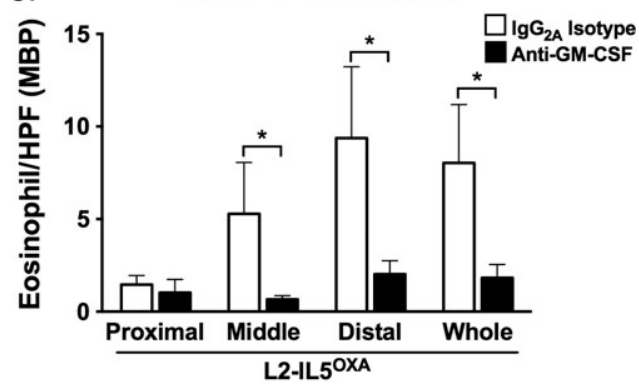

Cii Lamima propria eosinophilia

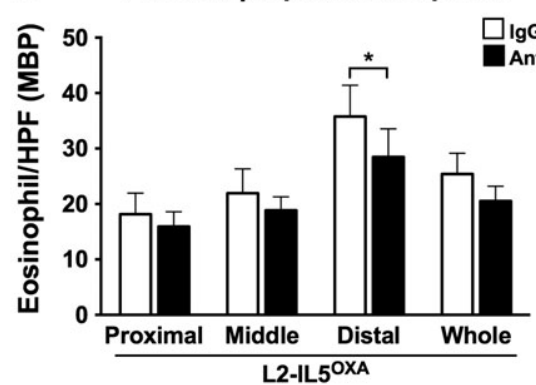

Ciii

Muscle eosinophilia

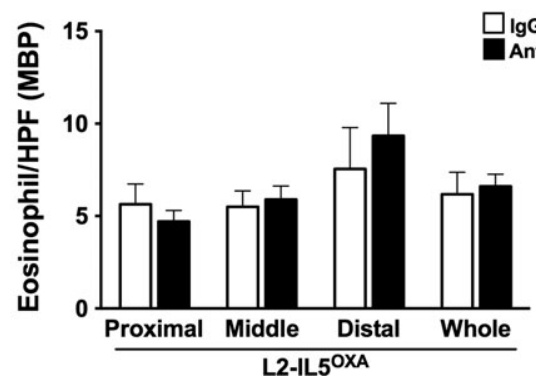

Figure 3 GM-CSF blockade limits epithelial eosinophilia in L2IL5 ${ }^{\text {OXA }}$ mice. Schematic of the induction of mouse eosinophilic esophagitis (EoE) (L2-IL5 ${ }^{\mathrm{OXA}}$ ) and the anti-GM-CSF treatment regimen used in these studies. Anti-GM-CSF antibody: Clone MP122E9, R\&D Systems MAB415. $0.5 \mathrm{mg} /$ mouse per dose. p.c. percutaneous, that is, intra-esophageal, i.p. intraperitoneal administration. (B) Representative MBP photomicrographs from the distal esophagus of control anti-IgG ${ }_{2 A}$-treated L2-IL5 ${ }^{\text {OXA }}$ EoE mice and
anti-GM-CSF-treated L2-IL5 ${ }^{\text {OXA }}$ EoE mice. (C) Eosinophils per highpowered field were quantified in each tissue compartment (epithelial, lamina propria, muscle) and esophageal site (proximal, middle, distal) and compared between L2-IL5 ${ }^{\mathrm{OXA}}$ EoE mice that underwent anti-GM-CSF to those that underwent anti-lgG $\mathrm{g}_{2 \mathrm{~A}}$ control antibody treatment. Statistical significance was assessed using the Students' $t$-test, $* P<0.05$. Data are expressed as means \pm SEM. 
Anti-GM-CSF antibody treatment does not affect esophageal eosinophil maturation, activation markers, or eosinophil chemoattractant expression

Given its role as an eosinophilopoietin, we examined whether depletion of GM-CSF during esophagitis would affect the maturation status of eosinophils in mice treated with anti-GM-CSF when compared to those treated with anti-IgG2a control (Fig. 4). We identified esophageal eosinophils by flow cytometry as $\mathrm{FSC}^{\text {hi }}$, $\mathrm{SSC}^{\text {hi }}$, live, single cells, CD45 ${ }^{+}$, and SiglecF ${ }^{+}$(Fig. 4A). We then examined these cells for the level of expression of various maturation and activation markers. We found no effect of anti-GMCSF on the expression levels of any of these selected markers (Fig. 4B). We also examined whether anti-GM-CSF would affect esophageal tissue expression of eosinophil chemokines CCL11 and CCL24 (eotaxins 1 and 2) and found no effect (Fig. 4C).

\section{A Esophageal eosinophilia}
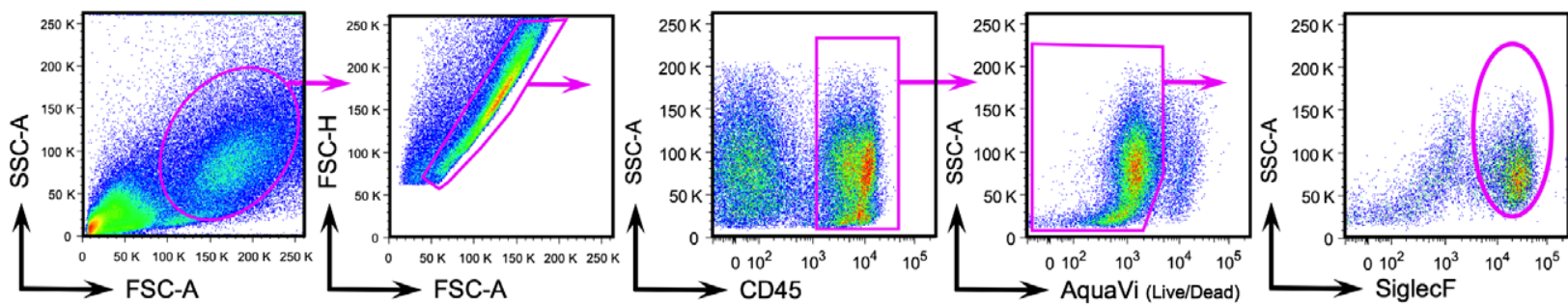

B Eosinophil maturation and activation markers

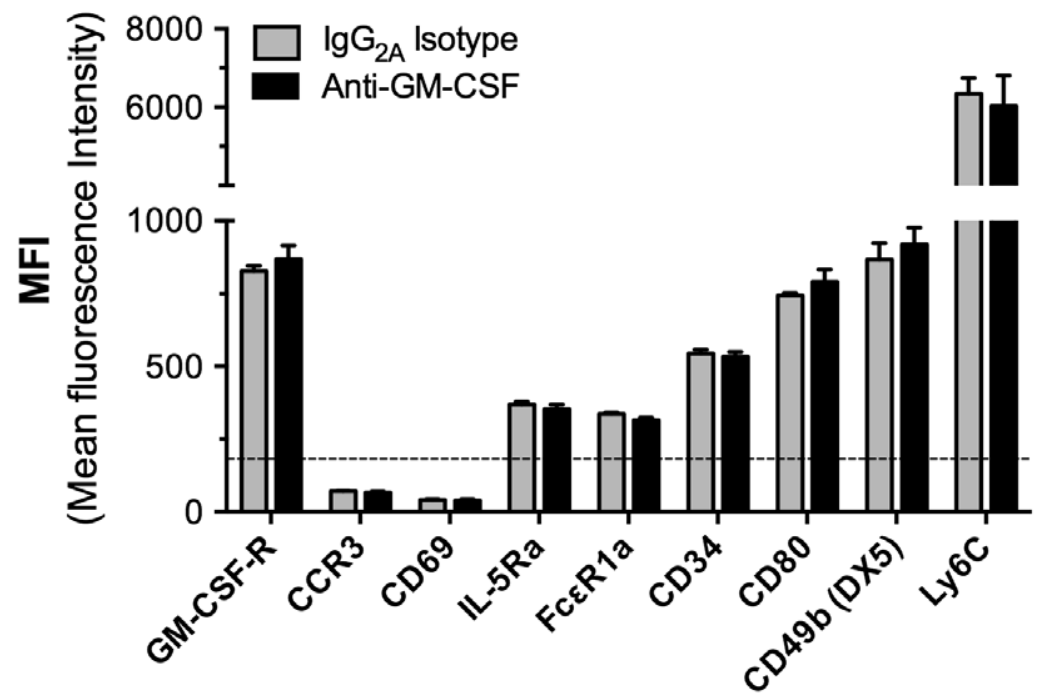

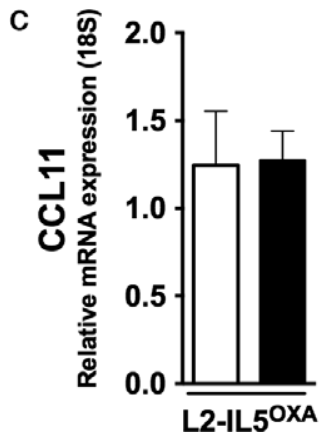

Figure 4 GM-CSF treatment does not affect eosinophil activation or maturation in L2-IL5 ${ }^{\mathrm{OXA}}$ mice. (A) Flow cytometric identification of esophageal eosinophils and (B) analysis of maturation and activation markers on eosinophils in L2-IL5 ${ }^{\text {OXA }}$ eosinophilic esophagitis (EoE) mouse esophagi comparing anti-GM-CSF antibody-treated to

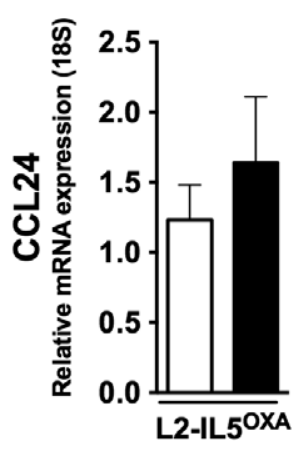

$\operatorname{lgG}_{2 \mathrm{~A}}$ isotype control antibody-treated mice. (C) Analysis of dista whole esophageal total mRNA for levels of the transcripts for CCL11 and CCL24 in L2-IL5 ${ }^{\text {OXA }}$ EoE mice comparing anti-GM-CSF to anti-lgG $\mathrm{G}_{2 \mathrm{~A}}$ control antibody-treated groups. No statistically significant differences were observed using Students' $t$-test. 
Anti-GM-CSF antibody treatment resolves basal cell hyperplasia and epithelial remodeling

Next, the effects of anti-GM-CSF depletion on epithelial remodeling and basal cell hyperplasia were assessed (Fig. 5). A substantial improvement in basal cell hyperplasia and the homeostatic localization of proliferative cells as demarcated by Ki67 immunohistochemistry was observed following treatment (Fig. 5A). When enumerated, the most significant improvement was observed in the proximal and distal esophagus (Fig. 5B).

\section{Anti-GM-CSF antibody treatment decreases blood vessel density and angiogenic factor production}

Finally, the role of GM-CSF in esophageal vascular remodeling in the context of eosinophilic inflammation was examined (Fig. 6). PECAM (CD31)-positive vessel density was enumerated, and it was found that anti-GM-CSF treatment resulted in a lower vessel density compared to $\mathrm{IgG}$ control-treated L2-IL5 ${ }^{\text {OXA }}$ animals (Fig. 6A,B). When the expression of angiogenic stimulating factors including angiogenin and angiopoietins 1 and 2 was assessed, it was also determined that anti-GM-CSF treatment led to significantly reduced levels of these growth factors (Fig. 6C-E). In addition, GMCSF blockade significantly decreased esophageal levels of endothelial markers PECAM and von Wilebrand Factor (vWF) compared to IgG-treated controls (Fig. 6F,G).
Interestingly, no difference in the expression levels of the activation markers CDH5, VCAM, or VEGF-A was detected (Fig. 6H-J). We also assessed each of these molecular markers in the context of uninflamed L2-IL5 ${ }^{\mathrm{VEH}}$ esophagi and found a significant decrease in selected markers (VWF: $40 \%$ decrease $\pm 4 \%, P<0.05$, ANG $2: \quad 60 \%$ decrease $\pm 11 \%$, $P<0.05$, PECAM: $62 \%$ decrease $\pm 16 \%, P<0.05)$ in the esophagi treated with anti-GM-CSF antibody when compared to L2-IL5 ${ }^{\mathrm{VEH}} \operatorname{IgG}$ control-treated animals. However, importantly, this did not lead to a decrease in the number of PECAM + blood vessels in anti-GM-CSF antibody-treated uninflamed L2-IL5 ${ }^{\mathrm{VEH}}$ mice $(0.08 \pm 0.03$ vs $0.07 \pm 0.02$, $P=0.75$; anti-GM-CSF-L2-IL5 ${ }^{\mathrm{VEH}}$ vs IgG-Ctrl-L2-IL5 ${ }^{\mathrm{VEH}}$ ). Thus, therapeutic intervention with anti-GM-CSF limits epithelial remodeling and angiogenic activation during active disease in the L2-IL5 ${ }^{\text {OXA }}$ model of EoE.

\section{Discussion}

In our studies, we directly examined the physiologic impact of targeting GM-CSF, a crucial eosinophilopoietin in the pathogenesis of esophageal eosinophilia and epithelial remodeling in the L2-IL5 ${ }^{\text {OXA }}$ mouse model of EoE. We demonstrated that GM-CSF expression is increased in the L2-IL5 ${ }^{\text {OXA }}$ mice and that a targeted antibody-mediated GM-CSF blockade results in a significant decrease in epithelial eosinophilia, decreased epithelial basal cell hyperplasia, and decreased angiogenesis, resulting in overall attenuation

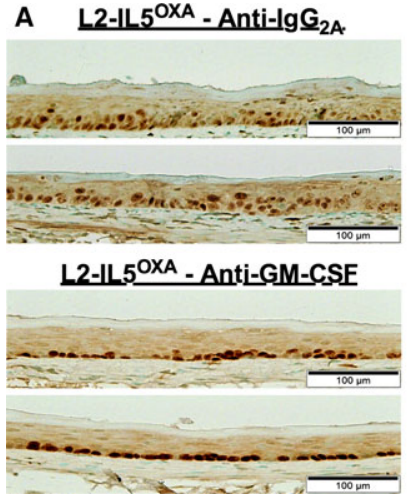

Figure 5 Anti-GM-CSF limits esophageal epithelial basal cell hyperplasia and proliferation in L2-IL5 ${ }^{\mathrm{XXA}}$ mice. (A) Representative Ki67 photomicrographs from the distal esophagus of control anti-lgGtreated L2-IL5 ${ }^{\text {OXA }}$ eosinophilic esophagitis (EoE) mice and anti-GMCSF-treated L2-IL5 ${ }^{\mathrm{OXA}}$ EoE mice. (B) Total numbers of Ki67-positive

B

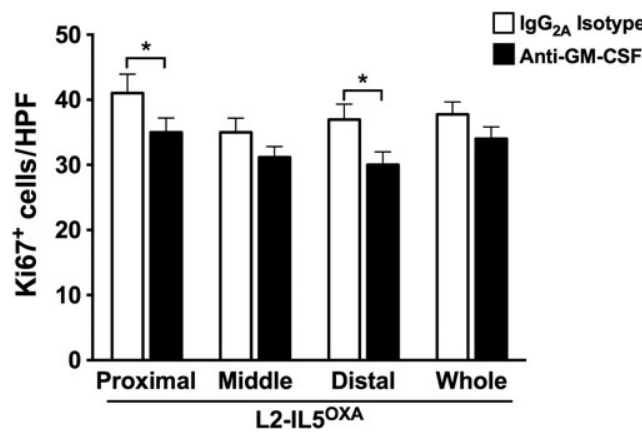

proliferating epithelial cells per high-powered field were quantified and compared between L2-IL5 OXA EoE mice that underwent anti-GM-CSF to those that underwent anti-IgG control antibody treatment. Statistical significance was assessed using the Students' $t$-test, $* P<0.05$. Data are expressed as means \pm SEM.
Figure 6 GM-CSF blockade attenuated angiogenesis and vascular remodeling in L2-IL5 ${ }^{\text {OXA }}$ mice. (A) Representative PECAM photomicrographs from the distal esophagus of anti-lgG-treated L2-IL5 OXA eosinophilic esophagitis (EoE) mice and anti-GM-CSF-treated L2IL5 ${ }^{\text {OXA }}$ EoE mice. (B) Average density of PECAM-positive vessels per $\mathrm{mm}^{2}$ was quantified and compared between L2-IL5 ${ }^{\mathrm{OXA}}$ EoE mice that underwent anti-GM-CSF to those that underwent anti-
IgG control antibody treatment. Analysis of distal whole esophageal total mRNA for levels of the transcripts for (C) ANG, (D) ANGPT1, (E) ANGPT2, (F) PECAM, (G) VWF, (H) CDH5, (I) VEGF-A, and (J) VCAM in L2-IL5 ${ }^{\text {OXA }}$ EoE mice comparing anti-GM-CSF to anti-lgG ${ }_{2 A}$ control antibody-treated groups. Statistical significance was assessed using the Students' $t$-test $* P<0.05$. Data are expressed as means \pm SEM. 
A

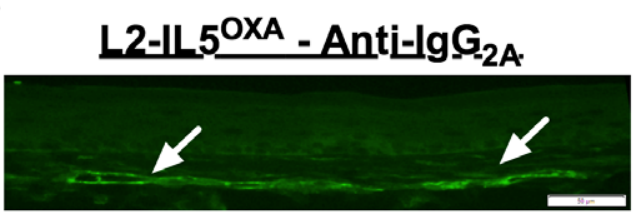

L2-IL5OXA - Anti-GM-CSE

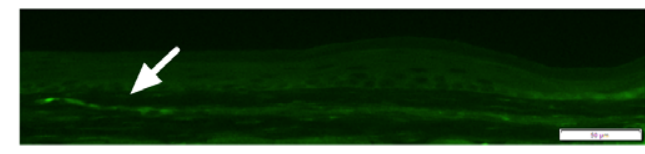

C
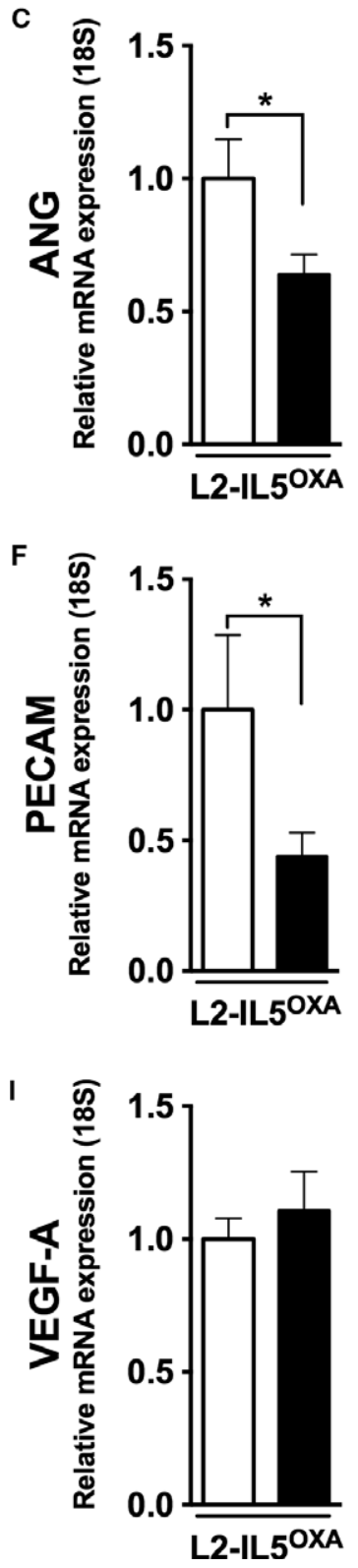

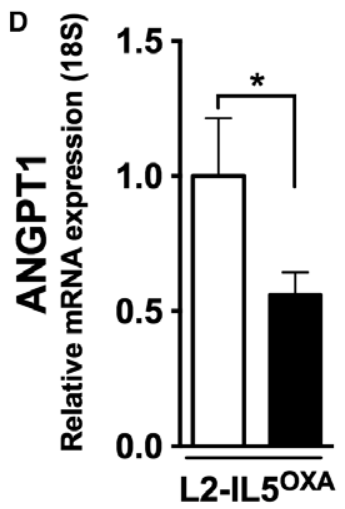

G
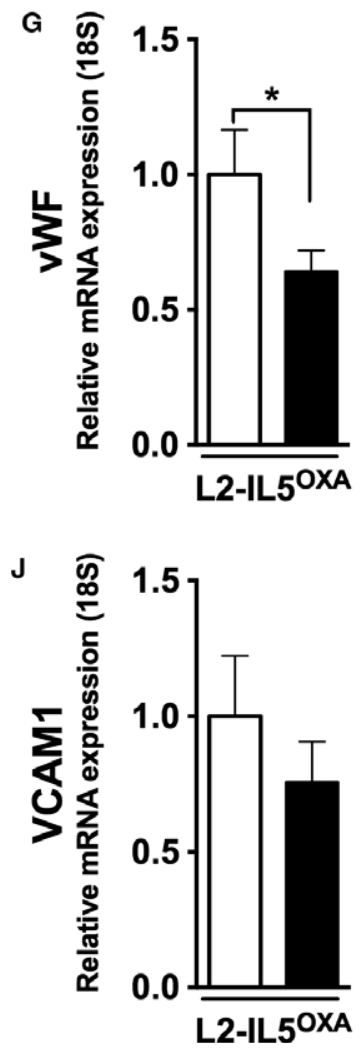

B
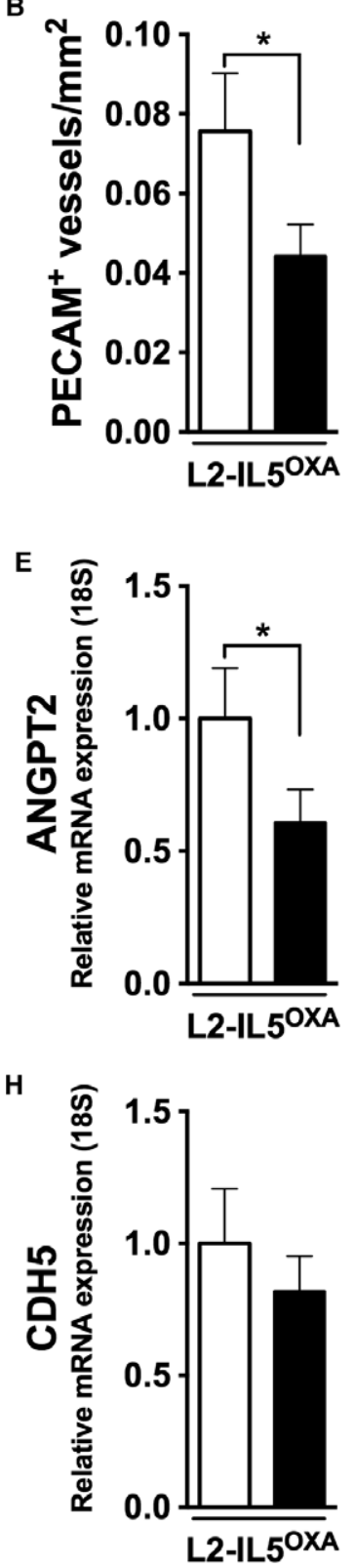

$\square \lg _{2 A}$ Isotype Anti-GM-CSF 
of EoE-like disease in this delayed-type hypersensitivity model. Collectively, these studies demonstrate that targeting GM-CSF plays an important role in reducing eosinophil numbers and remodeling in a mouse model of EoE.

Despite the fact that clinical intervention studies have shown that inhibition of another eosinophilopoietin interleukin (IL)-5 significantly reduced eosinophilia (21-26), these studies failed to demonstrate clinical benefit $(5,6)$. We sought to understand the potential role of another therapeutic target, GM-CSF, to address the need for alternative treatment options. Previous studies have demonstrated that targeting GM-CSF influences leukemogenesis in an in vitro model of chronic myelomonocytic leukemia (27), inflammatory responses in experimental arthritis $(28,29)$, reduced tissue macrophage in rat model of myocardial infarction (30), and reduced Amyloid $\beta 1-42$ and microglial activity in a mouse model of Alzheimer's disease (31). Two studies have also directly examined the influence of anti-GM-CSF therapy on bronchoalveolar lavage fluid eosinophilia in mouse models of allergic airway inflammation $(32,33)$, and an ongoing trial is examining anti-GM-CSF antibodies' role in subjects with asthma. Moreover, two human clinical trials are ongoing, studying the effects of anti-GM-CSF in rheumatoid arthritis $(34,35)$. While many preclinical and clinical studies targeting GM-CSF for inflammatory diseases are ongoing, the role of GM-CSF and the impact of anti-GM-CSF therapies in EoE have not been assessed to date.

Here, we provide evidence for the increased presence of GM-CSF and for its role in esophageal epithelial eosinophilia in the L2-IL5 ${ }^{\text {OXA }}$ mouse model of EoE. Previous studies using eotaxin ${ }^{-/}$genetically targeted mice in a mouse model of EoE still accumulated esophageal eosinophils, implicating additional chemotactic axes in esophageal epithelial recruitment (23). We show that reduced epithelial eosinophilia is not a result of effects of anti-GM-CSF treatment on esophageal eosinophilic chemokines eotaxin-1 or -2 or on eosinophil development and circulation. Granulocyte-macrophage colony-stimulating factor acts on mature eosinophils to elicit priming, migration, and degranulation (7-9). Here, we show no effect of anti-GM-CSF therapy on esophageal eosinophil expression of maturation or activation markers. These findings suggest that decreased esophageal epithelial eosinophilia in the L2-IL5 ${ }^{\text {OXA }}$ EoE mouse model may be acting through local effects of GM-CSF within the esophagus, possibly limiting intra-epithelial eosinophil survival or indirectly via antigen-presenting cells. Our data would also suggest that GM-CSF has a direct role of vascular activation and remodeling, which may also limit eosinophil trafficking to the inflamed esophagus. Previous literature supports the effects of GM-CSF on cells of the mature myeloid lineage including PMNs (polymorphonuclear leukocytes), monocytes/macrophage, basophils, and eosinophils (36). Here, we confirm the expression of esophageal GM-CSF-receptor-alpha in the L2IL5 ${ }^{\text {OXA }}$ mouse EoE model is primarily on eosinophils, and to a lesser extent on basophil- and MHCII-positive cells. Future studies need to examine the role of GM-CSF on all cells involved in EoE pathogenesis in order to elucidate why antiGM-CSF mostly affected epithelial eosinophilia and to model what effect an anti-GM-CSF therapy would have on chronic disease and/or esophageal remodeling.

Targeting eosinophilopoiesis (via IL-5 blockade) in both mouse models and in clinical trials have failed to demonstrate therapeutic efficacy in $\operatorname{EoE}(5,6)$. Granulocyte-macrophage colony-stimulating factor along with IL-5 and IL-3 are a triad of important, although thought to be potentially redundant, cytokines associated with eosinophil development in the bone marrow. This study demonstrates for the first time that anti-GM-CSF attenuates esophageal epithelial eosinophilia, epithelial, and vascular remodeling and implicates GM-CSF signaling as a potential therapeutic target that warrants further investigation in EoE.

As with any mouse model, translation to clinical relevance is critical. However, this study suggests GM-CSF is a potential target that may offer new opportunities for the clinical management of patients with EoE.

One of the limitations of our study is the dosing regimen used. More frequent administrations may have been more completely effective. Equally, mice were treated by intraperitoneal administration of antibody. Current therapeutic approach in patients with EoE selectively targets the esophagus with orally administered steroids. Future studies should consider a mechanism to directly target the esophagus with antibody, or indeed with other molecular-inhibiting methodologies. The focus of the current study was the net effect on eosinophils, the effects on maturation and survival, specifically in the esophagus with or without anti-GM-CSF treatment. Other physiological effects may be altered via GM-CSF suppression. These include effects on antigenpresenting cell(s) as well as the effects of GM-CSF on the epithelium in EoE. What is known is that GM-CSF is overproduced by keratinocytes in atopic dermatitis, and this has implications for dendritic cell activation (20). Our studies implicate anti-GM-CSF treatment in the reduction of angiogenic factors in the esophagus. In the human esophagus postirradiation and in a mouse model of esophageal overexpression of IKK $\beta \mathrm{ca}$, GM-CSF has been indicated in esophageal pro-angiogenic mechanisms $(16,37)$. Thus, the pleiotropic factor GM-CSF may play multiple roles in EoE via direct effects on other cells. Future studies will aid in determining the potential impact of GM-CSF on the broad array of cells involved in EoE, such as esophageal epithelial cells, endothelial cells, resident and infiltrating esophageal antigen-presenting cells, and their indirect effects on eosinophils.

In summary, the present study highlights an important role for esophageal GM-CSF in regulating inflammatory patterns in a mouse model of EoE. Esophageal GM-CSF is increased in the context of eosinophilic inflammation, and these studies support its involvement in esophageal eosinophilia, basal cell hyperplasia, and vascular remodeling as potential therapeutic targets for the treatment of EoE.

\section{Acknowledgments}

The authors wish to thank the members of the participating laboratories and the members of the Gastrointestinal Eosinophilic Diseases Program, Children's Hospital, Colorado, for 
insightful discussions and critical comments. We also wish to acknowledge the invaluable assistance in animal husbandry and care at University of Colorado School of Medicine (Kristann Magee) and the administrative support provided by Joshua Rosenfeld.

\section{Author contributions}

ENM, JCM, and GTF contributed to the study concept and design, drafted the manuscript, and performed study supervision; ENM, KAB, JH, HM, RH, and JCM involved in acquisition of data; ENM, JJL, GTF, and JCM performed analysis and interpretation of data; ENM, KAB, JH, RH, JJL, GTF, and JCM performed critical revision of the manuscript for important intellectual content; GTF and JCM obtained funding.

\section{Funding}

This work was supported by an investigator led grant from Morphotek Inc. The study sponsor was not involved in the experimental design, interpretation of results, or preparation of this article.

\section{Conflicts of interest}

Authors have no conflict of interests to report.

\section{References}

1. Dellon ES, Jensen ET, Martin CF, Shaheen NJ, Kappelman MD. Prevalence of eosinophilic esophagitis in the United States. Clin Gastroenterol Hepatol 2014;12:589-596.

2. Soon IS, Butzner JD, Kaplan GG, deBruyn JC. Incidence and prevalence of eosinophilic esophagitis in children. $J$ Pediatr Gastroenterol Nutr 2013;57:72-80.

3. Dellon ES. Diagnosis and management of eosinophilic esophagitis. Clin Gastroenterol Hepatol 2012;10:1066-1078.

4. Dellon ES, Gibbs WB, Rubinas TC, Fritchie KJ, Madanick RD, Woosley JT et al. Esophageal dilation in eosinophilic esophagitis: safety and predictors of clinical response and complications. Gastrointest Endosc 2010;71:706-712.

5. Straumann A, Conus S, Grzonka P, Kita H, Kephart G, Bussmann C et al. Anti-interleukin-5 antibody treatment (mepolizumab) in active eosinophilic oesophagitis: a randomised, placebo-controlled, double-blind trial. Gut 2010;59:21-30.

6. Assa'ad AH, Gupta SK, Collins MH, Thomson M, Heath AT, Smith DA et al. An antibody against IL-5 reduces numbers of esophageal intraepithelial eosinophils in children with eosinophilic esophagitis. Gastroenterology 2011;141:1593-1604.

7. Warringa RA, Koenderman L, Kok PT, Kreukniet J, Bruijnzeel PL. Modulation and induction of eosinophil chemotaxis by granulocyte-macrophage colony-stimulating factor and interleukin-3. Blood 1991;77:26942700.

8. Tai PC, Sun L, Spry CJ. Effects of IL-5, granulocyte/macrophage colony-stimulating factor (GM-CSF) and IL-3 on the survival of human blood eosinophils in vitro. Clin Exp Immunol 1991;85:312-316.

9. Fujisawa T, Abu-Ghazaleh R, Kita H, Sanderson CJ, Gleich GJ. Regulatory effect of cytokines on eosinophil degranulation. $J$ Immunol 1990;144:642-646.
10. Takahashi T, Kalka C, Masuda H, Chen D Silver M, Kearney $\mathrm{M}$ et al. Ischemia- and cytokine-induced mobilization of bone marrow-derived endothelial progenitor cells for neovascularization. Nat Med 1999;5:434438.

11. Ribatti D. Angiogenic activity of classical hematopoietic cytokines. Leuk Res 2012;36:537-543.

12. Bussolino F, Wang JM, Defilippi P, Turrini F, Sanavio F, Edgell CJ et al. Granulocyteand granulocyte-macrophage-colony stimulating factors induce human endothelial cells to migrate and proliferate. Nature 1989;337:471-473.

13. Bocchietto E, Guglielmetti A, Silvagno F, Taraboletti G, Pescarmona GP, Mantovani A et al. Proliferative and migratory responses of murine microvascular endothelial cells to granulocyte-colony-stimulating factor. J Cell Physiol 1993;155:89-95.

14. Masterson JC, McNamee EN, Hosford L, Capocelli KE, Ruybal J, Fillon SA et al. Local hypersensitivity reaction in transgenic mice with squamous epithelial IL-5 overexpression provides a novel model of eosinophilic oesophagitis. Gut 2014;63:43-53.

15. Wirtz S, Neufert C, Weigmann B, Neurath MF. Chemically induced mouse models of intestinal inflammation. Nat Protoc 2007;2:541-546.

16. Tetreault MP, Weinblatt D, Ciolino JD, Klein-Szanto AJ, Sackey BK, Twyman-Saint Victor $\mathrm{C}$ et al. Esophageal expression of active IkappaB kinase-beta in mice up-regulates tumor necrosis factor and granulocytemacrophage colony-stimulating factor, promoting inflammation and angiogenesis. Gastroenterology 2016;150:1609-1619.

17. Masterson JC, McNamee EN, Jedlicka P, Fillon S, Ruybal J, Hosford L et al. CCR3 blockade attenuates eosinophilic ileitis and associated remodeling. Am J Pathol 2011;179:2302-2314
18. Harada H, Nakagawa H, Oyama K, Takaoka M, Andl CD, Jacobmeier B et al. Telomerase induces immortalization of human esophageal keratinocytes without p16INK4a inactivation. Mol Cancer Res 2003;1:729-738.

19. Hancock GE, Kaplan G, Cohn ZA. Keratinocyte growth regulation by the products of immune cells. J Exp Med 1988;168:13951402.

20. Pastore S, Fanales-Belasio E, Albanesi C, Chinni LM, Giannetti A, Girolomoni G. Granulocyte macrophage colony-stimulating factor is overproduced by keratinocytes in atopic dermatitis. Implications for sustained dendritic cell activation in the skin. $J$ Clin Invest 1997;99:3009-3017.

21. Mishra A, Rothenberg ME. Intratracheal IL-13 induces eosinophilic esophagitis by an IL-5, eotaxin-1, and STAT6-dependent mechanism. Gastroenterology 2003;125:14191427.

22. Mishra A, Wang M, Pemmaraju VR, Collins MH, Fulkerson PC, Abonia JP et al. Esophageal remodeling develops as a consequence of tissue specific IL-5-induced eosinophilia. Gastroenterology 2008;134:204214.

23. Mishra A, Hogan SP, Brandt EB, Rothenberg ME. An etiological role for aeroallergens and eosinophils in experimental esophagitis. J Clin Invest 2001;107:83-90.

24. Mishra A, Hogan SP, Brandt EB, Rothenberg ME. IL-5 promotes eosinophil trafficking to the esophagus. $J$ Immunol 2002;168:2464-2469.

25. Akei HS, Mishra A, Blanchard C, Rothenberg ME. Epicutaneous antigen exposure primes for experimental eosinophilic esophagitis in mice. Gastroenterology 2005;129:985-994.

26. Rayapudi M, Mavi P, Zhu X, Pandey AK, Abonia JP, Rothenberg ME et al. Indoor insect allergens are potent inducers of 
experimental eosinophilic esophagitis in mice. J Leukoc Biol 2010;88:337-346.

27. Padron E, Painter JS, Kunigal S, Mailloux AW, McGraw K, McDaniel JM et al. GMCSF-dependent pSTAT5 sensitivity is a feature with therapeutic potential in chronic myelomonocytic leukemia. Blood 2013;121:5068-5077.

28. van Nieuwenhuijze AE, van de Loo FA, Walgreen B, Bennink M, Helsen M, van den Bersselaar L et al. Complementary action of granulocyte macrophage colony-stimulating factor and interleukin-17A induces interleukin-23, receptor activator of nuclear factor-kappaB ligand, and matrix metalloproteinases and drives bone and cartilage pathology in experimental arthritis: rationale for combination therapy in rheumatoid arthritis. Arthritis Res Ther 2015; 17:163.

29. Plater-Zyberk C, Joosten LA, Helsen MM, Koenders MI, Baeuerle PA, van den Berg WB. Combined blockade of granulocytemacrophage colony stimulating factor and interleukin 17 pathways potently suppresses chronic destructive arthritis in a tumour necrosis factor alpha-independent mouse model. Ann Rheum Dis 2009;68:721-728.
30. Kellar RS, Lancaster JJ, Thai HM, Juneman E, Johnson NM, Byrne HG et al. Antibody to granulocyte macrophage colony-stimulating factor reduces the number of activated tissue macrophages and improves left ventricular function after myocardial infarction in a rat coronary artery ligation model. J Cardiovasc Pharmacol 2011;57:568-574.

31. Manczak M, Mao P, Nakamura K, Bebbington C, Park B, Reddy PH. Neutralization of granulocyte macrophage colonystimulating factor decreases amyloid beta 1-42 and suppresses microglial activity in a transgenic mouse model of Alzheimer's disease. Hum Mol Genet 2009;18:3876-3893.

32. Cates EC, Fattouh R, Wattie J, Inman MD, Goncharova S, Coyle AJ et al. Intranasal exposure of mice to house dust mite elicits allergic airway inflammation via a GM-CSFmediated mechanism. $J$ Immunol 2004; 173:6384-6392.

33. Cates EC, Gajewska BU, Goncharova S, Alvarez D, Fattouh R, Coyle AJ et al. Effect of GM-CSF on immune, inflammatory, and clinical responses to ragweed in a novel mouse model of mucosal sensitization. $J$ Allergy Clin Immunol 2003;111:1076-1086.
34. Behrens F, Tak PP, Ostergaard M, Stoilov R, Wiland P, Huizinga TW et al. MOR103, a human monoclonal antibody to granulocyte-macrophage colony-stimulating factor, in the treatment of patients with moderate rheumatoid arthritis: results of a phase $\mathrm{Ib} /$ IIa randomised, double-blind, placebo-controlled, dose-escalation trial. Ann Rheum Dis 2015;74:1058-1064.

35. Kivitz A, Hazan L, Hoffman K, Wallin BA. FRI0209 MORAb-022, an anti-granulocyte macrophage-colony stimulating factor (GM$\mathrm{CSF}$ ) monoclonal antibody (MAB): results of the first study in patients with mild-tomoderate rheumatoid arthritis (RA). Ann Rheum Dis 2016;75(Suppl. 2):507.

36. Hamilton JA. GM-CSF in inflammation and autoimmunity. Trends Immunol 2002;23:403408.

37. Koukourakis MI, Flordellis CS, Giatromanolaki A, Koukouraki S, Kapsoritakis A, Potamianos S et al. Oral administration of recombinant human granulocyte macrophage colony-stimulating factor in the management of radiotherapy-induced esophagitis. Clin Cancer Res 1999;5:3970-3976. 